\title{
Microturbine power plant for utilization of the heat of exhaust gases of internal combustion engines
}

\author{
Yury Matveev, Marina Cherkasova, Viktor Rassokhin, Viktor Barskov*, Victor Chernikov, \\ Konstantin Andreev, Nikolay Kortikov, Oksana Nikiforova, Vladimir Yadikin \\ National Technology Initiative Center for Advanced Manufacturing Technologies based on the Institute \\ of Advanced Manufacturing Technologies of Peter the Great St. Petersburg Polytechnic University \\ Polytechnicheskaya, 29, St.Petersburg, 195251, Russia
}

\begin{abstract}
The article is devoted to the investigation and development of microsteam turbine unit of the LPI design for utilization of heat of exhaust gases of internal combustion engines. This installation will reduce the world carbon dioxide emissions, as well as add useful power for the needs of the consumer. Efficiency and environmental friendliness of the engine will increase. The article discusses development of the main directions of improvement of high-loaded steps of LPI, expansion of modern outlooks on the directions of MRI development and the use of LPI steps in the systems of heat recovery of exhaust gases of the internal combustion engine. The possibility to utilize the heat of exhaust gases of internal combustion engines by means of a turbine unit and the subsequent receipt of additional useful capacities are investigated in many developed countries of the world. Germany, Sweden, Japan, PRC and other leading countries in the automotive industry are intensively conducting works in this direction. The results of such studies have already found application in some freight cars. In the Russian market, this type of turbine is spread very weakly. Turbine unit behind the internal combustion engine works in conditions of low volumetric consumption of the working fluid, which leads to a decrease in the heights of the flow parts of the guides and working grids, because of which the relative gaps in the seals increase. This leads to the growth of leakage of the working fluid. On the other hand, a high degree of pressure reduction when choosing single-stage turbines leads to supersonic
\end{abstract}

\footnotetext{
*Corresponding author: viktorbarskov@mail.ru
} 
speeds in the flow part and increased losses due to powerful shock waves. Turbine unit efficiency under these operating conditions is low and needs additional research.

\section{Introduction}

Many factors affect the choice of working fluid for the organic Rankin cycle (ORC) such as energy source, operating temperature range, pressure and power level of the turbine installation. The choice of working fluid for ORC is considered in many works [1-6]. The thermodynamic cycle model is often used to compare the characteristics of working fluids. This is an important criterion of comparison and essentially depends on the physico-chemical properties of the working fluid. However, working fluid with high thermal efficiency may require conditions that lead to high costs. For instance, the use of water requires heaters with high temperature and pressure in the cycle. Therefore, the use of steam in the cycle is efficient only at relatively high power. As a result, the problem of choosing the optimal substance is multicriterial and has been considered in a number of works [7, 8]. A literature review on the suitable working fluids for combustion engine exhaust gases heat recovery has shown that methanol, isopentane, ethanol, water, R245fa, oktamethyltrisiloxane are the most suitable for examination and comparison [9-12]. Further deeper investigation of working fluids [13-15] and their application in the turbine installation was carried out on the basis of [16-20]. We carried out simulation of the turbine unit on the basis of studies on the optimal choice of the working fluid of the turbine unit, which utilizes exhaust heat of internal combustion motors. Based on the calculations, a three-dimensional model was built for the numerical study. Due to the small size of the installation and high parameters of its work, a simulation of a full-scale model on the air was carried out.

\section{Methods}

The article presents the model test of the turbine plant. It consists of several stages: preliminary and optimization for further research.The parameters of working fluid were recalculated for air for a model experiment.The numerical simulation of the operating conditions of the turbine unit were made using the methods of threedimensional computational gas dynamics.

A preliminary calculation of the engine was carried out to determine the geometric, gas and thermodynamic parameters. Using a mathematical model for calculating the supersonic single-stage micro-steam turbine of the LPI design, we determined the dependences of the nozzle height, the available power and the characteristic number $u / C_{0}$ on the average diameter of the turbine wheel. The low exit angle $\alpha_{1}=3 \ldots 9^{\circ}$ of the nozzle grating is one of the features of the LPI turbines. The degree of reactivity was chosen equal to 0.166 to create an active stage. The ratio $D_{\text {average }} / 1$ is greater than 8 to select the height of the blade. This condition allows performing design of blades with radial form of active surfaces. A small blade height is obtained $(11<1 \mathrm{~mm})$ with a degree of partialness equal to one, which leads to large terminal losses. 
Preliminary parameters of the turbine designed for ethanol are presented in Ошибка!

Источник ссылки не найден.. Combustion engine exhaust gases heat recovery turbine has an average diameter of $0.064 \mathrm{~m}$ and vane height of $0.003 \mathrm{~m}$. Operating rotation speed is $105000 \mathrm{rpm}$. Partial admission degree is $70 \%$ in operating point. Characteristic number $u / C_{0}$ equal to 0.46 corresponds to the single-stage turbine.

Table 1.Preliminary turbine parameters.

\begin{tabular}{|c|c|c|c|}
\hline & Symbol & Meas.unit & Value \\
\hline Power available & $N_{a v}$ & $\mathrm{~W}$ & 11494.0 \\
\hline Average diameter & $D_{a v e}$ & $\mathrm{~mm}$ & 60.4 \\
\hline Characteristic number & $u / C_{0}$ & - & 0.46 \\
\hline Vane height & $l_{l}$ & $\mathrm{~mm}$ & 3.2 \\
\hline Partial admission degree & $\varepsilon$ & - & 0.7 \\
\hline Number of nozzles & $z_{c}$ & $\mathrm{pcs}$ & 2 \\
\hline Nozzle throat & $D_{\min }$ & $\mathrm{mm}$ & 1.0 \\
\hline Rotation speed & $n$ & $\mathrm{rpm}$ & 105000.0 \\
\hline
\end{tabular}

\section{Results and Discussion}

Turbine optimization was carried out using mathematical model based on experimental characteristics of kinetic energy loss in blades and nozzles wheels, which were studied in wide range of geometrical and operating parameters. Mathematical model of a single-stage LPI-design micro turbine is a complete modeling algorithm composed of separate blocks in which processes in the flow passage of the turbine are described taking into account their connections and mutual influence. Block model of the flow passage part contains the basic equations describing thermal gas-dynamic processes, the submodel for determining energy and mass flow loss coefficients, as well as computational procedures for solving equations, approximation and logical deployment [16]. This optimization work allowed obtaining the main parameters of the turbine (Ошибка! Источник ссылки не найден.), such as: blade height $h_{b}=7 \mathrm{~mm}$; nozzle assembly geometric expansion degree $f_{c}=F_{\text {out }} F_{\text {critical }}=1$; nozzle assembly geometric inlet angle $\alpha_{l g}=5 \mathrm{deg}$; number of nozzles $Z_{n}=18$; trailing edge thickness $\Delta_{\text {edge }}=0.3 \mathrm{~mm}$. This data are necessary for further profiling of the turbine stage.

Table 2.Main parameters of turbine.

\begin{tabular}{|c|c|c|c|c|}
\hline № & Name & Symbol & Meas. unit & Value \\
\hline 1 & Degree of the reaction & $\rho_{t}$ & & 0.166 \\
\hline 2 & Mach number in nozzle assembly & $M_{1 t}$ & & 2.634 \\
\hline 3 & Static pressure at the turbine outlet & $P_{2}$ & Pa & 81000 \\
\hline 4 & Total temperature in relative frame & $T_{1}{ }^{*}$ & $\mathrm{~K}$ & 403.9 \\
\hline 5 & $\begin{array}{c}\text { Mach number for blade wheel outlet in } \\
\text { relative frame }\end{array}$ & $M_{2 t}$ & - & 1.825 \\
\hline
\end{tabular}




\begin{tabular}{|c|c|c|c|c|}
\hline № & Name & Symbol & Meas. unit & Value \\
\hline 6 & Blade wheel outlet velocity & $C_{2}$ & $\mathrm{~m} / \mathrm{s}$ & 208.0 \\
\hline 7 & Power of turbine & $N$ & $\mathrm{~kW}$ & 12.2 \\
\hline 8 & Power available & $N_{a v}$ & $\mathrm{~kW}$ & 18.64 \\
\hline 9 & Efficiency ratio & $h_{B}$ & & 0.654 \\
\hline 10 & Total efficiency ratio & $h^{*}$ & & 0.721 \\
\hline 11 & Outlet total temperature & $T_{2}{ }^{*}$ & $\mathrm{~K}$ & 322.9 \\
\hline 12 & Outlet total pressure & $P_{2}^{*}$ & $\mathrm{~Pa}$ & 119057.9 \\
\hline 13 & Mass flow & $G$ & $\mathrm{~kg} / \mathrm{s}$ & 0.052 \\
\hline
\end{tabular}

In order for the results of further numerical modeling to be considered reliable, their verification with real experiments is necessary.This turbine unit has very small dimensions of average wheel diameter and blade height, which makes it difficult, if not impossible, to use probes to measure flow parameters inside the turbine flow section. The initial gas parameters are high and difficult to achieve in the existing laboratory conditions. Therefore, the simulation was carried out on the air full-scale turbine in compliance with the geometric, kinematic and dynamic similarity. The characteristics of the model turbine are shown in table 3.

Table 3.Parameters turbine.

\begin{tabular}{|c|l|c|c|c|}
\hline № & \multicolumn{1}{|c|}{ Dimension } & Value & $\begin{array}{c}\text { Full-scale } \\
\text { turbine }\end{array}$ & Model turbine \\
\hline 1 & Mach number, $\mathrm{M}_{\mathrm{c} 1}$ & - & 2.634 & 2.644 \\
\hline 2 & Inlet pressure, $\mathrm{p}_{0}{ }^{*}$ & $\mathrm{~Pa}$ & $3.6 \cdot 10^{6}$ & $0.8 \cdot 10^{6}$ \\
\hline 3 & Inlet temperature, $\mathrm{T}_{0}{ }^{*}$ & $\mathrm{~K}$ & 530 & 343 \\
\hline 4 & Working fluid & - & Etanol & Air \\
\hline 5 & Mass flow, $\mathrm{G}$ & $\mathrm{kg} / \mathrm{s}$ & 0.052 & 0.045 \\
\hline 6 & Characteristic number $u / C_{0}$ & - & 0.396 & 0.396 \\
\hline 8 & Rotor speed, $\mathrm{n}$ & $\mathrm{rpm}$ & 105000 & 30000 \\
\hline 9 & Power of turbine, $\mathrm{N}_{\mathrm{t}}$ & $\mathrm{Wt}$ & 12.2 & 3.7 \\
\hline 10 & Reynolds number, $\mathrm{Re}$ & - & $0.52944 \cdot 10^{6}$ & $0.63524 \cdot 10^{6}$ \\
\hline
\end{tabular}

Numerical simulation method is used to study the characteristics of the flow structure in the flow part of the turbine stage. It provides information on the structure of the flow field in the step in addition to the data, obtained in field experiments or in experiments on a model turbine. The necessity of this method in this work is determined by the peculiarities of the studied flow part. In the experiment it is impossible to use measuring probes in the flow part due to the small geometrical dimensions. The method of numerical simulation is used in addition to the aerodynamic experiment to reduce the time and cost by reducing the number of experiments on a model turbine. It seems possible to judge the efficiency of the workflow in the stage and develop ways to improve it based on detailed data on the flow structure in the stage obtained by numerical simulation.

Basing on the two-dimensional calculation and subsequent optimization of geometrical data we designed the model of a low-cost turbine.

This stage refers to the type of low-consumption and small-sized turbines. The average diameter of the impeller is $103.5 \mathrm{~mm}$. The height of the working blades is $12 \mathrm{~mm}$, the blades have an active profile. 
The nozzle is installed in front of the impeller and consists of two nozzles. The angle of the flow output from nozzles is 5 degrees.

The construction of the grid model for the numerical simulation of the flow in the flow part of the turbine installation was carried out using the ANSYS ICEM software for the nozzle (Figure 2) and Numeca software for the impeller (Figure 1).

Near the surfaces limiting the flow in the flow part (working and end surfaces), the grid is thickened, which makes it necessary to calculate the flow parameters in the boundary layer.The parameter $\mathrm{y}+$ (dimensionless distance from the first grid point to the wall) was chosen in the range from 30 to 50 , that is, a high-Reynolds model of turbulence was used. In such models, the modified near-wall functions are used, which provide a weak sensitivity of the results to the position of the first grid point near the wall.

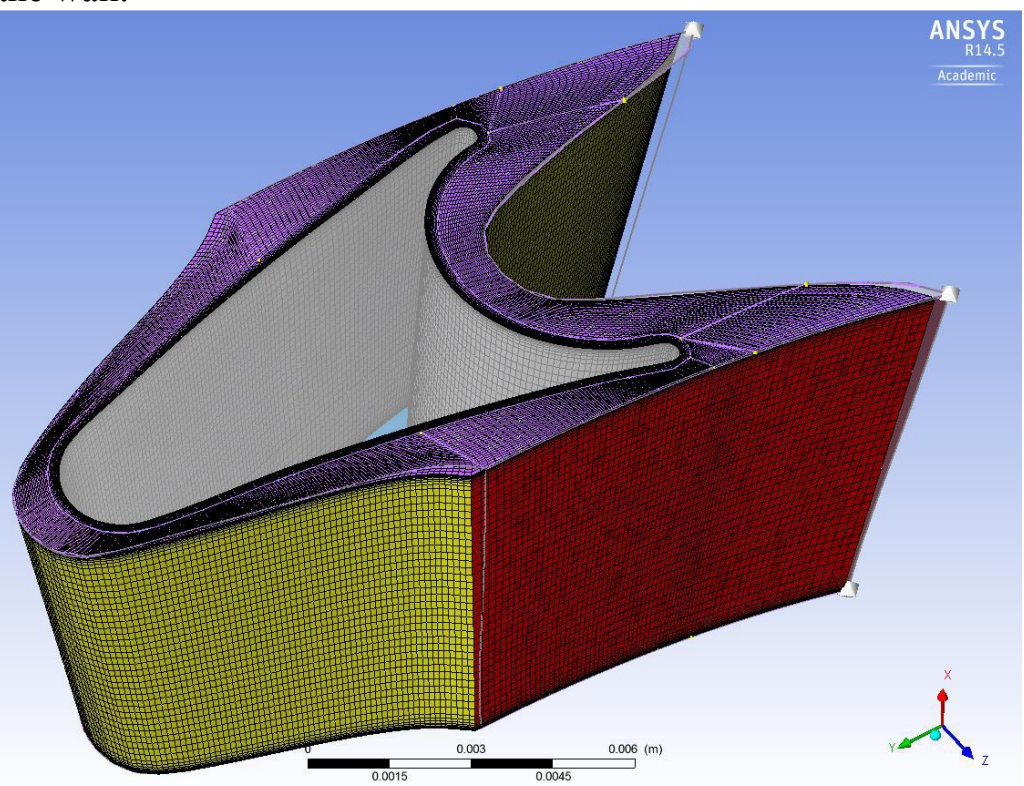

Fig.1. Grid for a working blade.

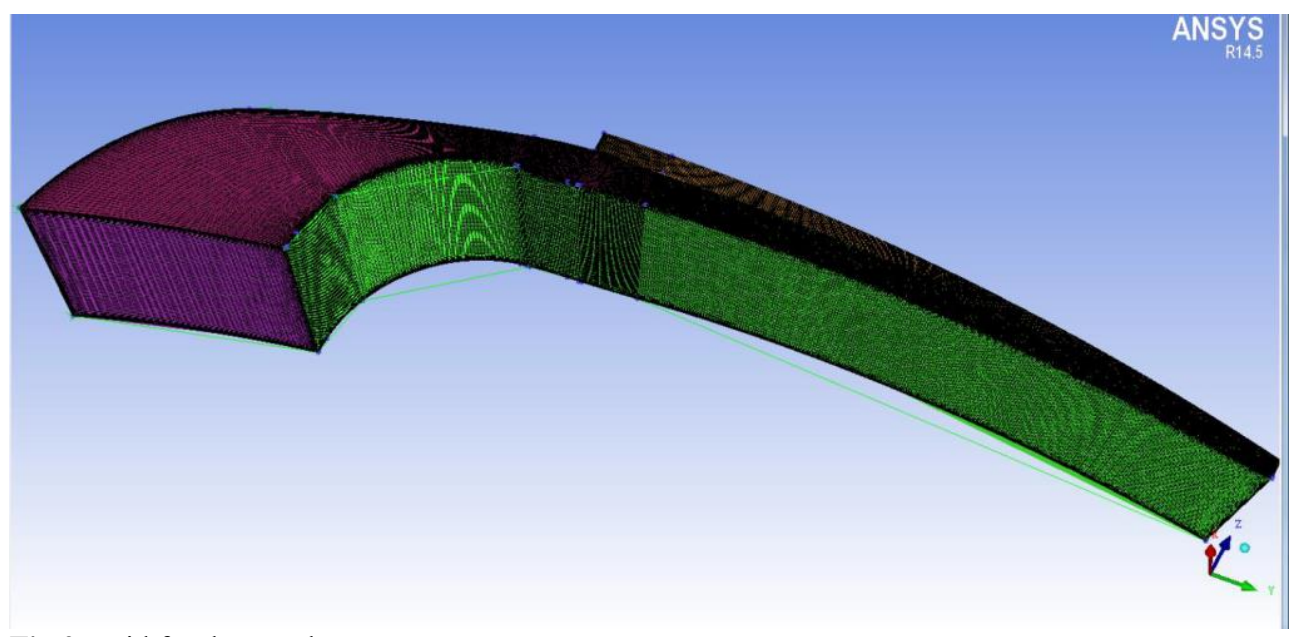

Fig.2. Grid for the nozzle 
The number of items per channel was 2809154 .

The gas-dynamic flow field is determined by the nozzle geometry, physical properties of the working fluid, boundary conditions at the entrance to the nozzles, and exit from the impeller. The presence of viscous friction and turbulence of the flow during the gas flow process is accompanied by losses of the available kinetic energy. According to the results of the calculation, it is possible to identify the main factors determining the losses in the nozzle apparatus. Stream field is presented in Figure.3.

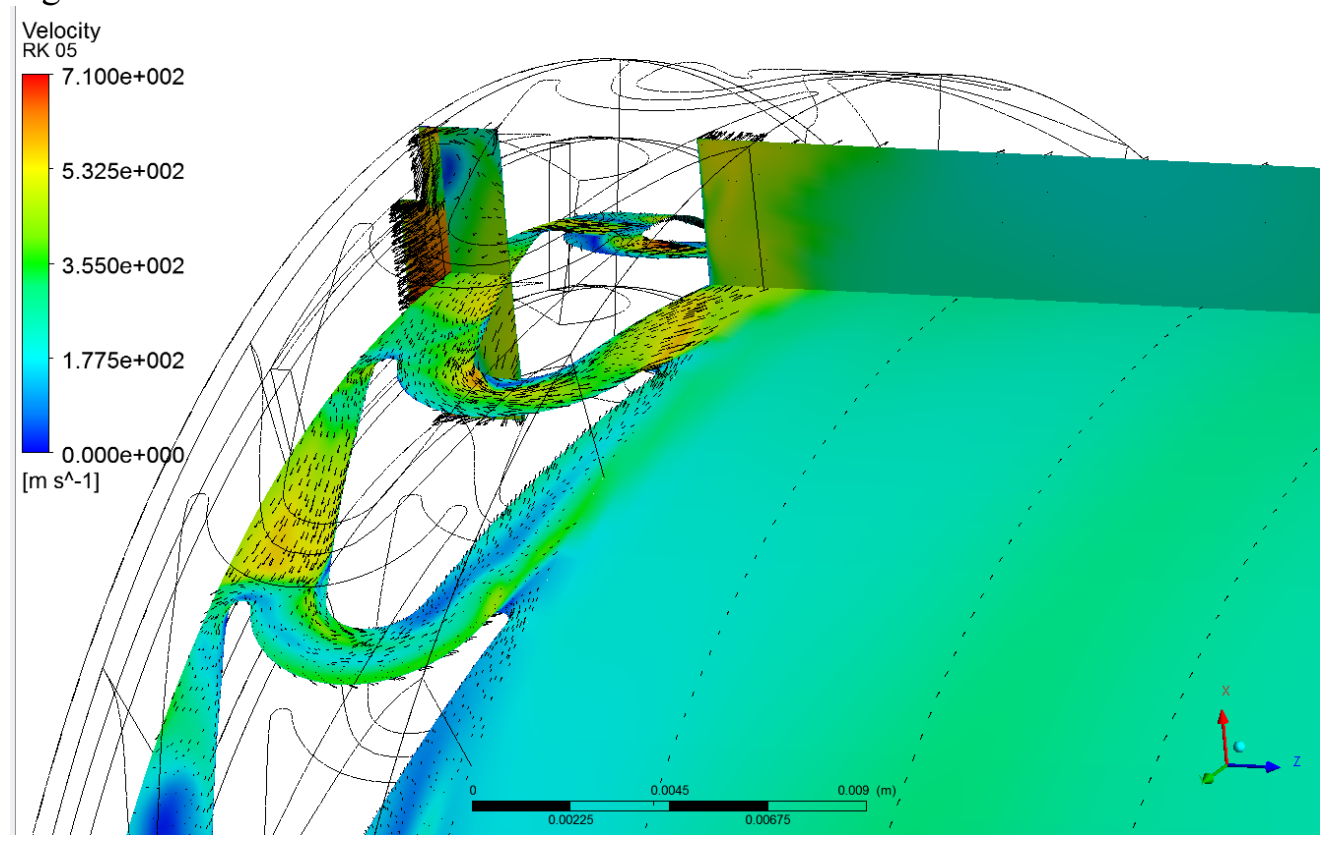

Fig.3.Velocity field in the turbine stage

As a result of the performed work, the possibility of creating a microturbine installation with an LPI design stage for combustion engine exhaust gases heat recovery was shown. A study was conducted on the choice of the optimal working fluid. Ethanol has demonstrated the best parameters from thermodynamic and economic points of view. Microturbine stage was developed for the following parameters of the working fluid: $P_{0}=3.6 \mathrm{MPa}, T_{0}=530 \mathrm{~K}, n=105000 \mathrm{rpm}, G=0.052$ $\mathrm{kg} / \mathrm{s}$.

Design and optimization were carried out according to the methods developed at the Department of Turbines, Hydro Machines and Aircraft Engines of Peter the Great St. Petersburg Polytechnic University. The efficiency of the turbine stage is quite high and equals to 0.645 in static parameters and 0.721 in total parameters. The analysis shows that the LPI design turbine stage is effective and allows one to develop recommendations for designing and optimizing the turbine stage. The designed stage will reduce gas emission from the combustion engine and increase the power for customer needs, efficiency and environmental friendliness of the engine. 
Nevertheless, theoretical calculations based on empirical equations and existing experience in designing such turbines must be verified in practice. For this propose, it is planned to further study this stage using the test rig. Numerical simulations will also be carried out to reduce the cost of a practical experiment.

\section{Conclusions}

Upon completion of the research work, the findings and recommendations on the development of principles for the construction of the microturbine with low-flow LPI design turbine stage for combustion engine exhaust gases heat recovery can be used in the creating and commissioning of this type of turbines. A micro-steam turbine unit was developed for the following working fluid parameters: $\mathrm{P}_{0}=3.96 \mathrm{MPa}$, $\mathrm{T}_{0}=530 \mathrm{~K}, \mathrm{n}=105000 \mathrm{rpm}, \mathrm{G}=0.052 \mathrm{~kg} / \mathrm{s}$.

The numerical experiment was carried out using software packages ANSYS (ICEM и CFX) and Numeca. Comparison of numerical methods with onedimensional calculations showed good convergence. The efficiency of the installation according to one-dimensional calculations is equal to 0.65 ; according to the results of a numerical experiment the efficiency is 0.63 . The analysis made it possible to investigate the structure of the flow in the flow section of the turbine and to develop recommendations for optimizing the micro-steam turbine installation of the LPI design.This unit will reduce exhaust gas emissions from the internal combustion engine and add useful power for the needs of the consumer, increase the efficiency and environmental friendliness of the engine.

\section{References}

1. Chen H., Goswami D.Y., Stefanakos E.K. Renewable and Sustainable Energy Reviews, vol. 14, pp. 3059- 3067(2010)

2. Saleh B., Koglbauer G., Wendland M., Fischer J. Energy, vol. 32, pp. 1210-1221(2007)

3. Drescher U., Brüggemann D. Applied Thermal Engineering, vol. 27, pp. 223-228(2007)

4. Tchanche B.F., Papadakis G., Lambrinos G., Frangoudakis A. Applied Thermal Engineerin, vol. 29, no. 11-12, pp. 2468- 2476(2009)

5. Mikielewicz D., Mikielewicz J. Applied Thermal Engineering, vol. 30, pp. 23572362(2010)

6. Lakew A.A., Bolland O. Applied Thermal Engineering, vol. 30, pp. 1262-1268(2010)

7. Stijepovic M.Z., Linke P., Papadopoulos A.I., Grujic A.S. Applied Thermal Engineering, vol. 36, pp. 406-413(2012)

8. Wang Z.Q., Zhou N.J., Guo J., Wang X.Y. Energy, vol. 40, iss. 1, pp. 107-115(2012)

9. Oomori, H. and Ogino, S. SAE Technical Paper 930880, doi:10.4271/930880(1976)

10. Patel, P. and Doyle, E. SAE Technical Paper 760343, 1976, doi:10.4271/760343

11. El Chammas, R. and Clodic, D. SAE Technical Paper 2005-01-1171, doi:10.4271/200501-1171(2005)

12. HaraldKunte, JoergSeume. SAE Technical Paper 2013-24-0092, doi:10.4271/2013-240092(2013)

13. Dillon, H.E. and Penoncello, S.G. Int. J. Thermophys., 25(2):321-335, 2004

14. DeReuck, K.M. Blackwell Scientific Publications, London (1993)

15. Wagner, W. and Pruss, A. Phys. Chem. Ref. Data, 31(2):387-535 (2002) 
16. V. Rassokhin, V. Busurin, V. Sadovnichy. Innovative high technologies for Russia, p.39 (1995)

17. V.Rassokhin, N. Golovin, V. Sadovnichy. Scientific and Technical Conference RAS (1997)

18. N. Zabelin, G. Rakov, V. Rassokhin. SPbPU Journal of Engineering Science and Technology №1(166)(2013)

19. A. Epifanov, A. Kirillov, V. Rassokhin. SPbPU Journal of Engineering Science and Technology, №1(142) (2012)

20. N. Zabelin, G. Rakov, G. Fokin. SPbPU Journal of Engineering Science and Technology, №3(178)(2013)

21. M. Cherkasova., V. Rassokhin N. Zabelin. ES3 Web of Conferences №91, 01001 (2019) 